\title{
Detection of Giardia intestinalis Assemblages A, B and D in Domestic Cats from Warsaw, Poland
}

\author{
DOROTA JAROS ${ }^{\star 1,2}$, WOJCIECH ZYGNER², SŁAWOMIR JAROS ${ }^{3,4}$ and HALINA WĘDRYCHOWICZ ${ }^{2,3}$ \\ ${ }^{1}$ Institute for Medical Biology of the Polish Academy of Sciences, Łódź, Poland \\ ${ }^{2}$ Division of Parasitology and Parasitic Diseases, Department of Preclinical Sciences, Faculty of Veterinary Medicine, \\ Warsaw University of Life Sciences, Warsaw, Poland \\ ${ }^{3}$ Laboratory of Molecular Parasitology, W. Stefanski Institute of Parasitology PAS, Warsaw, Poland \\ ${ }^{4}$ Laboratory of Molecular Biology, Mabion Ltd., Łódź, Poland
}

Received 7 February 2011, revised 30 June 2011, accepted 10 July 2011

\begin{abstract}
Giardia intestinalis is a complex species divided into 7 assemblages $(A-G)$. Two of them (A and B) are infective for both humans and animals. In cats four assemblages can occur: A, B, D, and F. Assemblages A and B infect either cats, dogs and humans, assemblage D infects cats and dogs and assemblage F only cats. The purpose of this study was to determine the prevalence and genotypes of G. intestinalis in cats from Warsaw. From November 2006 to March 2007 a hundred sixty samples of stool were collected and examined by light microscopy. G. intestinalis cysts were detected in $3.75 \%$ of samples. DNA extracted from positive samples was used as template for PCR-RFLP using Giardia specific primers and the amplicons were sequenced. A comparison of the obtained DNA sequences with the Giardia sequences in the GeneBank database revealed assemblage A in $1.25 \%$ of the investigated cats, assemblage B in $1.25 \%$ and D in $1.25 \%$.
\end{abstract}

Ke y w ords: Giardia intestinalis, assemblage in cats, genotype, PCR-RFLP, zoonosis

\section{Introduction}

The protozoan parasite Giardia intestinalis infects vertebrates including humans, domestic and wild animals. This parasite can cause gastrointestinal infections ranging from mild to severe as well as chronic diseases. Giardia is one of the most common causes of diarrhoea in humans and the most frequent parasite of companion animals. Usually symptoms occur in six to fifteen days after infection. In the acute stage symptoms can last from two to four days, and after that a chronic phase can appear and can last from a few weeks to several years. However the disease is usually self-limiting and asymptomatic infections are common (Flanagan, 1992; Farthing, 1997; Singer and Nash, 2000; Adam, 2001). The potential health risk to humans from gastrointestinal parasites remains a significant problem throughout the world (Schantz, 1994). The main origin of infection is water contaminated with Giardia cysts (Karanis et al., 2007). However, food, especially raw vegetables, may be also contaminated with Giardia cysts. In addition, infection may be transmitted by direct person-to-person or person-to-animal contact, especially in communities with poor standards of hygiene (Hunter and Thompson, 2005). The prevalence of human giardiosis in the world ranges from $0.004 \%$ to almost $100 \%$, and the most prevalent infections are detected in children $<2$ years in developing countries. The mean prevalence in Europe, North America and Australia is $0-32 \%$, depending on region and age group. In Poland the prevalence of Giardia infection observed in humans is $0.04-9 \%$, but children are infected more frequently than adults. In cats the prevalence of infection observed in the world is 0.6 to $80 \%$, but in Poland the prevalence is rather low $(1.3 \%)$. However only a few studies were performed (Zygner and Wędrychowicz 2008; Bajer et al., 2009).

The species G. intestinalis includes seven assemblages A-G, that can be characterized using, for example, the glutamate dehydrogenase (gdh), smallsubunit (SSU) rRNA, and triosephosphate isomerase (tpi) genes (Monis et al., 1999; van Keulen et al., 2002; Read et al., 2004; Caccio et al., 2005; Papini et al., 2007). Assemblages A and B infect humans and other hosts, including cats (Monis et al., 1998; Monis et al., 1999; Thompson et al., 2000; van Keulen et al., 2002; Monis et al., 2003). Assemblage C infects only dogs, D infects

\footnotetext{
* Corresponding author: D. Jaros, Division of Parasitology and Parasitic Diseases, Department of Preclinical Sciences, Faculty of Veterinary Medicine, Warsaw University of Life Sciences; Ciszewskiego Str. 8, 02-786 Warsaw, Poland; phone +48 22 5936044; fax +48 22 593648; e-mail: djaros@cbm.pan.pl
} 
dogs and cats and assemblage $\mathrm{F}$ infects cats alone (Santíni et al., 2006; Souza etal., 2007; Palmer et al., 2008). Zoonotic transmission of G. intestinalis is still under consideration despite increasing knowledge of the molecular identification of Giardia from different hosts (Monis et al., 2003; Thompson, 2004; Hunter and Thompson, 2005). Although Majewska (1994) showed zoonotic potential of Giardia, the reservoir of infection for humans is still unknown. In Poland assemblages A and $\mathrm{B}$ were detected in faecal samples from humans. However, in that study Giardia cysts were not detected in humans who had had permanent contact with animals (Solarczyk et al., 2010).

The aim of this study was to analyse the genetic diversity of Giardia isolates from clinical cases among cats in Warsaw, Poland by gdh PCR-(RFLP) assay and the single $g d h$ gene PCR assays. The different sequences were used to construct a database so it was possible to compare the result of this study with sequences previously published and available in the GenBank database.

\section{Experimental}

\section{Materials and Methods}

Giardia cysts were identified in the Division of Parasitology and Parasitic Diseases, Faculty of Veterinary Medicine, Warsaw University of Life Sciences. Fecal samples were collected from November 2006 to May 2007 in the Small Animal Clinic, Department of Clinical Sciences, Faculty of Veterinary Medicine, Warsaw University of Life Sciences. In total 160 cat stool samples were collected. Giardiosis was diagnosed by detection of cysts in fecal samples using Meridian MeriFluor ${ }^{\oplus}$ Cryptosporidium/Giardia test according to manufacturer procedure (Meridian Diagnostics Inc.).

DNA was extracted from all positive fecal samples using a stool extraction kit (QIAamp DNA stool kit, QIAGEN). A DNA fragment (about $770 \mathrm{bp}$ ) of the gdh gene was amplified using PCR-RFLP with primer GDH1 (5' ATC TTC GAG AGG ATG CTT GAG 3') and GDH4 (5’ AGT ACG CGA CGC TGG GAT ACT 3') as reported Homan et al. (1998). This method allowed to distinguish between assemblages A and B by RFLP analysis. Amplification was performed on a total reaction volume of $50 \mu \mathrm{l}$, containing template DNA and the following PCR mixture: $10 \times$ Taq Reaction buffer, $2 \mathrm{mM}$ $\mathrm{MgCl}_{2}, 0.2 \mathrm{mM}$ dNTPs, 1.25 units of Taq DNA polymerase (Fermentas) and $0.5 \mu \mathrm{M}$ of each primer. The conditions of PCR were as follows: initially $94^{\circ} \mathrm{C}$ for $3 \mathrm{~min}$, then 35 cycles of $94^{\circ} \mathrm{C}$ for $30 \mathrm{~s}, 56^{\circ} \mathrm{C}$ for $30 \mathrm{~s}$ and $72^{\circ} \mathrm{C}$ for $60 \mathrm{~s}$, and finally, after these cycles, $72^{\circ} \mathrm{C}$ for $10 \mathrm{~min}$ (Homan et al., 1998). The reactions were performed in a PTC 200 Thermal Cycler (MJ Research).
The PCR products were visualized by electrophoresis in $1 \%$ agarose gel with ethidium bromide. In all cases, the PCR products were gel purified using a gel extraction kit (Macherey - Nagel), and sequenced using an AbiPrism 3100 and GeneScan Analysis Software. The PCR products were sequenced in both directions using either GDH1 or GDH4 primers. Results were compared with sequences available in the GenBank database.

The PCR products were purified using a gel extraction kit (Macherey - Nagel), and then digested with $D d e \mathrm{I}$ in a reaction mixture of $2 \mu \mathrm{l}$ of $10 \times$ buffer, $1 \mu \mathrm{l}$ of $D d e I, 5 \mu \mathrm{l}$ purified PCR products and distilled water to a final volume of $20 \mu \mathrm{l}$ at $37^{\circ} \mathrm{C}$ for $1 \mathrm{hr}$. The digested mixtures were analysed by electrophoresis in $2 \%$ agarose gel with ethidium bromide (Homan et al., 1998).

To be able to amplify and distinguish all assemblages, a distinct fragment of the $g d h$ gene (220 bp) was amplified. The $g d h$ gene fragment was amplified using the forward primer GDHF3 (5'-TCC ACC CCT CTG TCA ACC TTT C-3') and the reverse primer GDHB5 (5'-AAT GTC GCC AGC AGG AAC G-3') as reported Itagaki et al. (2005). PCR reaction mixtures consisted of $0.5 \mu \mathrm{M}$ of each primer, $0.2 \mathrm{mM}$ of each dNTP, $2 \mathrm{mM}$ $\mathrm{MgCl}_{2}, 1$ unit of Taq DNA polymerase (Fermentas) and $10 \times$ Taq Reaction buffer (Fermentas). The reactions were performed on a total reaction volume of $25 \mu$ l. The conditions of the PCR were as follows: initially $94^{\circ} \mathrm{C}$ for $3 \mathrm{~min}$, then $35 \mathrm{cycles}$ of $94^{\circ} \mathrm{C}$ for $30 \mathrm{~s}, 59^{\circ} \mathrm{C}$ for $30 \mathrm{~s}$ and $72^{\circ} \mathrm{C}$ for $30 \mathrm{~s}$, and finally, after all these cycles, $72^{\circ} \mathrm{C}$ for 10 min (Itagaki et al., 2005). The reactions were performed in a PTC 200 Thermal Cycler (MJ Research). The products of PCR were visualized by electrophoresis in $2 \%$ agarose gel with ethidium bromide. The PCR products were gel purified using the same kit mentioned above and sequenced using an AbiPrism 3100 and GeneScan Analysis Software. PCR products were sequenced in both directions using either GDHF3 or GDHB5. The results were compared with sequences available in the GenBank database.

\section{Results}

Microscopic analysis of the 160 samples proved that only 6 (3.75\%) were positive for Giardia cysts. In PCR-RFLP 770 bp products were obtained (Fig. 1a) in 4 cases. After RFLP analysis two of them were recognized as assemblage $A$ and another two as assemblage $B$ (Fig. 1b). A comparison of all four sequences from PCR-RFLP with those from the GeneBank database allowed to identify them as fragments of G. intestinalis gdh gene and confirmed RFLP analysis. The sequencing and genotyping of two amplicons (220 bp) obtained from PCR using starters GDHF3 and GDHB5 revealed assemblage D (Fig. 1c). 


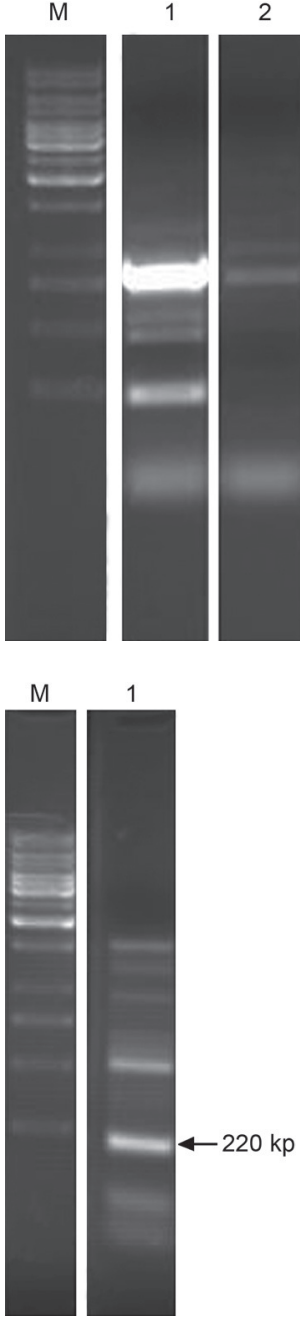

Fig. 1C. Restriction patterns of $g d h$ gene amplified with GDH1 and GDH4. Lanes: M, $1 \mathrm{~kb}$ molecular weight marker (Fermentas); lane 1 izolate (B) from cat.

\section{Discussion}

The potential risk to human health from G. intestinalis infections remains a meaningful problem all over the world. Recent studies on parasites of dogs and cats have demonstrated that the levels of Giardia infections were higher than expected (Johnson and Gasser, 1993; Bugg et al., 1999; Itoh et al., 2006). Previous studies on feline giardiosis suggested a significant problem for human health because of the potential risk for zoonotic transmission (Robertson et al., 2000; Thompson et al., 2000; van Keulen et al., 2002; Read et al., 2004; Thompson, 2004). However, many scientists claimed that most cat infections were caused by assemblages D or F, non-pathogenic for human (Monis et al., 1998; Monis et al., 1999; van Keulen et al., 2002; Monis et al., 2003). In European countries, the genotypic characterization of $G$. intestinalis infections in cats has received little attention and very few isolates have been characterized (Berrilli et al., 2004; Lalle et al., 2005; Papini et al., 2007). In this study, four out of six Giardia positive cats had assemblages A or B potentially pathogenic for human. Therefore, the results of this study suggest that the population of Warsaw cats may pose a risk to

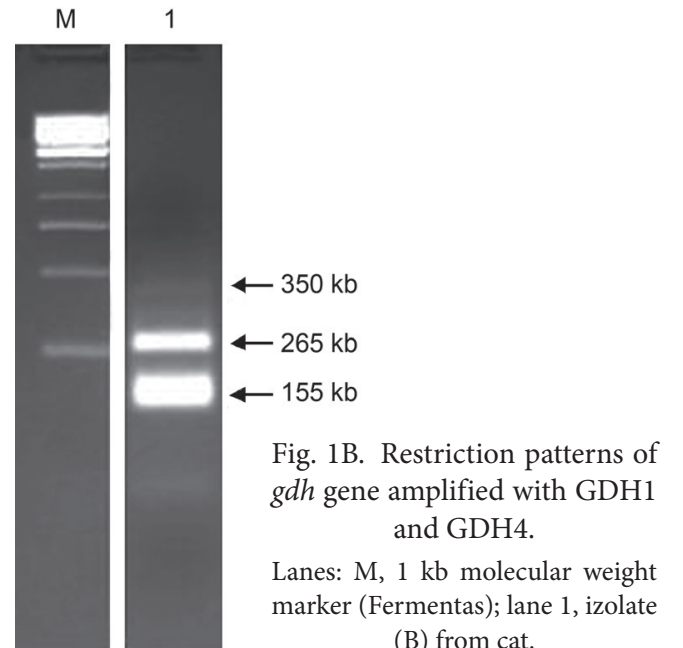

(B) from cat.

human health because of the possibility of zoonotic transmission.

Feline giardiosis has been found all over the world and detection rates in particular regions fluctuate from $0.58 \%$ to $60 \%$. In USA, $0.58 \%$ of cats out of 631021 examined possessed Giardia infection (De Santis-Kerr et al., 2006), in Japan $40 \%$ of cats were infected out of 600 examined (Itoh et al., 2006), in Turkey $22.4 \%$ of cats had it out of 100 examined (Cirak and Bauer, 2004). The prevalence may depend to a high degree on the method used for diagnosis. For instance, in Australia 5.6\% or $60 \%$ of cats out of 40 were reported to be infected, using PCR and ELISA respectively (McGlade et al., 2003). Also, in the Czech Republic $0.74 \%$ or $56.9 \%$ out of 107 investigated cats were found to be infected using conventional microscopic techniques or ELISA, respectively (Svobodova et al., 1995). These differences result from the different specificity and sensitivity of the tests. Last study showed that specificity and sensitivity of an ELISA test compared with fluorescent antibody test amounted 0.96 and 0.51 respectively. However, positive predictive value was rather poor at prevalence rates $10 \%$ or less (Rishniw et al., 2010). Thus, it is highly probable that the results of that test may be false positive rather than true positive. Moreover, Cirak and Bauer (2004) showed that another ELISA test was more often positive in microscopically Giardia-negative fecal samples in which Isospora spp. oocysts were detected than in samples without any parasites. This result may indicate cross-reactions in ELISA tests used in animals.

The sensitivity and specificity of light microscopy used in this study highly depends on the experience and knowledge of technician or researcher, but PCR tests are more objective, highly sensitive and specific (Prichard and Tait 2001; Barr, 2006; Allenspach and Gaschen, 2008). Nantavisai et al. (2007) showed that the sensitivity and specificity of PCR method for detection of Giardia DNA is $97.3 \%$ (95\% confidence interval, $87.9-99.9 \%$ ) and $100 \%$ (95\% confidence interval, 
91.3-100\%), respectively. However, sensitivities of different PCR tests are also variable. This depends on primers used for amplification of different target gene locus. Nantavisai et al. (2007) showed that PCR test with primers compatible for SSU rRNA gene fragment detected Giardia DNA in concentration of $10 \mathrm{pg} / \mu \mathrm{l}$ DNA per PCR mixture while PCR test with primers compatible for Triosephosphate isomerase gene fragment detected Giardia DNA in minimal concentration of $1000 \mathrm{pg} / \mu \mathrm{l}$. The primers compatible for glutamate dehydrogenase gene fragment used in this study were moderately sensitive. This primer set allows to detect Giardia DNA in minimal DNA concentration of $1000 \mathrm{pg} / \mu \mathrm{l}$, but minimal Giardia cyst concentration detected by this primer set was 337 cysts/ml of fecal sample, while primers compatible for Triosephosphate isomerase gene fragment allowed to detect Giardia DNA when minimal cyst concentration was 3368 cysts $/ \mathrm{ml}$.

The results of this study differ from the results of previous studies. In Japan and Australia all or all but one cats were infected with non-pathogenic for humans assemblage F (Itagaki et al., 2005, Palmer et al., 2008). However, in Brazil 42.1\% Giardia infections were caused by assemblage $A$, and the remaining cats were infected with assemblage F (Souza et al., 2007). In Italy Papini et al. (2007) detected only assemblage A in all examined samples of cat feces. These differences can result from the fact that there are few researches on genotyping of G. intestinalis infections in cats. The importance of Warsaw cats in the transmission of G. intestinalis to humans cannot be finally evaluated because of the small number of positive samples. However, the results of this work and that from Brazil (Souza et al., 2007) show there is a potential risk of human infection. Therefore, it is necessary to assume that a cat infected with Giardia possesses potentially zoonotic assemblages.

\section{Literature}

Adam R.D. 2001. Biology of Giardia lamblia. Clin. Microbiol. 14: 447-475.

Allenspach K. and F.P. Gaschen 2008. Small Intestinal Disease, pp.187-202. In: Steiner J.M. (ed). Small Animal Gastroenterology. Schlütersche Verlagsgesellschaft mbH \& Co.KG, Hannover.

Bajer A., M. Bednarska and E. Siński. 2009. Twenty years of Cryptosporidium spp. and Giardia spp. investigations in Poland (in Polish). Wiad Parazytol 55: 301-304.

Barr S.C. 2006. Giardiasis, pp. 736-742. In: Greene C.E. (ed). Infectious Diseases of the Dog and Cat. Saunders Elsevier, St. Louis, M.O. Berrilli F., D. Di Cave, C. D’Orazi, P. Orecchia, L. Xhelilaj, D. Bejko, P. Caça, D. Bebeci, F. Cenko, D. Donia and others. 2004. Prevalence and genotyping of human isolates of Giardia duodenalis from Albania. Parasitol. Int. 55: 295-297.

Bugg R.J., I.D. Robertson, A.D. Elliot and R.C.A. Thompson. 1999. Gastrointestinal parasites of urban dogs in Perth, Western Australia. Vet. J. 157: 295-301.
Caccio S.M., R.C.A. Thompson, J. McLaughlin and H.V. Smith. 2005. Unravelling Cryptosporidium and Giardia epidemiology. Trends. Parasitol. 21: 430-437.

Cirak V.Y. and C. Bauer. 2004. Comparison of conventional coproscopical methods and commercial coproantigen ELISA kits for the detection of Giardia and Cryptosporidium infections in dogs and cats. Berl. Munch. Tierarztl. Wochenschr. 117: 410-413.

De Santis-Kerr A.C., M. Raghavan, N.W. Glickman, R.J. Caldanaro, G.E. Moore, H.B. Lewis, P.M. Schantz and L.T. Glickman. 2006. Prevalence and risk factors for Giardia and coccidia species of pet cats in 2003-2004. J. Feline. Med. Surg. 8: 292-301.

Farthing M.J. 1997. The molecular pathogenesis of giardiasis. J. Pediatr. Gastroenterol. Nutr. 24: 79-88.

Flanagan P.A. 1992. Giardia - diagnosis, clinical course and epidemiology. Epidemiol. Infect. 109: 1-22.

Homan W.L., M. Gilsing, H. Bentala, L. Limper and F. van Knapen. 1998. Characterization of Giardia duodenalis by polymerase-chainreaction fingerprinting. Parasitol. Res. 84: 707-714.

Hunter P.R. and R.C.A. Thompson. 2005. The zoonotic transmission of Giardia and Cryptosporidium. Int. J. Parasitol. 35: 1-10.

Itagaki T., S. Kinoshita, M. Aoki, N. Itoh, H. Saeki, N. Sato, J. Uetsuki, S. Izumiyama, K. Yagita and T. Endo. 2005. Genotyping of Giardia intestinalis from domestic and wild animals in Japan using glutamete dehydrogenase gene sequencing. Vet. Parasitol. 144: 283-287.

Itoh N., N. Muraoka, J. Kawamata, M. Aoki and T. Itagaki. 2006. Prevalence of Giardia intestinalis infection in household cats of Tohoku District in Japan. Parasitology 68: 161-163.

Johnson J. and R.B. Gasser. 1993. Copro-parasitological survey of dogs in South-Victoria. Aust. Vet. Pract. 23: 127-131.

Karanis P., C. Kourenti and H. Smith. 2007. Waterborne transmission of protozoan parasites: a worldwide review of outbreaks and lessons learnt. J. Water. Health. 5: 1-38.

Lalle M., E. Pozio, G. Capelli, F. Bruschi, D. Crotti and S.M. Cacciò. 2005. Genetic heterogeneity at the beta-giardin locus among human and animal isolates of Giardia duodenalis and identification of potentially zoonotic subgenotypes. Int. J. Parasitol. 35: 207-213. Majewska A.C. 1994. Successful experimental infections of a human volunteer and Mongolian gerbils with Giardia of animal origin. Trans. R. Soc. Trop. Med. Hyg. 88: 360-362.

McGlade T.R., I.D. Robertson, A.D. Elliot and R.C. Thompson. 2003. High prevalence of Giardia detected in cats by PCR. Vet. Parasitol. 110: 197-205.

Monis P.T., R.H. Andrews, G. Mayrhofer, J. Mackrill, J. Kulda, J.L. Isaac-Renton and P.L. Ey. 1998. Novel lineages of Giardia intestinalis identified by genetic analysis of organisms isolated from dogs in Australia. Parasitology 116: 7-19.

Monis P.T., R.H. Andrews, G. Mayrhofer and P.L. Ey. 1999. Molecular systematics of the parasitic protozoan Giardia duodenalis. Mol. Biol. Evol. 16: 1135-1144.

Monis P.T., P.T. Andrews, G. Mayrhofer and P.L. Ey. 2003. Genetic diversity within the morphological species Giardia intestinalis and its relationship to host origin. Infect. Genet. Evol. 3: 29-38.

Nantavisai K., M. Mungthin, P. Tan-ariya, R. Rangsin, T. Naaglor and S. Leelayoova. 2007. Evaluation of the Sensitivities of DNA Extraction and PCR Methods for Detection of Giardia duodenalis in Stool Specimens. J. Clin. Microbiol. 45: 581-583.

Papini R., G. Cardini, B. Paoletti and A. Giangaspero. 2007. Detection of Giardia assemblage A in cats in Florence, Italy. Parasitol. Res. 100: 653-656.

Palmer C.S., R.J. Traub, I.D. Robertson, G. Devlin, R. Rees and R.C. Thompson. 2008. Determining the zoonotic significance of Giardia and Cryptosporidium in Australian dogs and cats. Vet. Parasitol. 154: 142-147.

Prichard R. and A. Tait. 2001. The role of molecular biology in veterinary parasitology. Vet Parasitol 98: 169-194. 
Read C.M., P.T. Monis and R.C.A. Thompson. 2004. Discrimination of all genotypes of Giardia duodenalis at the glutamate dehydrogenase locus using PCR-RFLP. Infect. Genet. Evol. 4: 125-130. Rishniw M., J. Liotta, M. Bellosa, D. Bowman and K.W. Simpson. 2010. Comparison of 4 Giardia Diagnostic Tests in Diagnosis of Naturally Acquired Canine Chronic Subclinical Giardiasis. J. Vet. Intern. Med. 24: 293-297.

Robertson I.D., P.J. Irwin, A.J. Lymbery and R.C. Thompson. 2000. The role of companion animals in the emergence of parasitic zoonoses. Int. J. Parasitol. 30: 1369-1377.

Santíni M., J.M. Trout, J.A. Vecino, J.P. Dubey and R. Fayer. 2006. Cryptosporidium, Giardia and Enterocytozoon bieneusi in cats from Bogota (Colombia) and genotyping of isolates. Vet. Parasitol. 141: 334-339.

Schantz P.M. 1994. Of worms, dogs and human hosts: continuing challenges for veterinarians in prevention of human disease. J. Am Vet. Med. Assoc. 204: 1023-1028.

Singer S.M. and T.E. Nash. 2000. The role of normal flora in Giardia lamblia infection in mice. J. Infect. Dis. 181: 1510-1512.

Solarczyk P., A. Werner and A.C. Majewska. 2010. Genotyping human isolates from west-central Poland. Wiad. Parazytol. 56: 171-177.
Souza S.L.P., S.M. Gennari, L.J. Richtzenhain, H.F. Pena, M.R. Funada, A. Cortez, F. Gregori and R.M. Soares. 2007. Molecular identification of Giardia duodenalis isolates from humans, dogs, cats and cattle from the state of São Paulo, Brazil, by sequence analysis of fragments of glutamate dehydrogenase $(g d h)$ coding gene. Vet. Parasitol. 149: 258-264.

Svobodova V., M. Svoboda and J. Konvalinova. 1995. Comparison of the detection of Giardia intestinalis cysts with the presence of specific antibodies in dogs and cats. Vet. Med. 40: 141-146.

Thompson R.C.A., R.M. Hopkins and W.L. Homan. 2000. Nomenclature and genetic groupings of Giardia infecting mammals. Parasitol Today 16: 210-213.

Thompson R.C.A. 2004. The zoonotic significance and molecular epidemiology of Giardia and giardiasis. Vet. Parasitol. 126: $15-35$.

van Keulen H., P.T. Macechko, S. Wade, S. Schaaf, P.M. Wallis and S.L. Erlandsen. 2002. Presence of human Giardia in domestic, farm and wild animals, and environmental samples suggests a zoonotic potential for giardiasis. Vet. Parasitol. 108: 97-107.

Zygner W. and H. Wędrychowicz. 2008. Animals as giardiasis reservoir for humans (in Polish). Post. Mikrobiol. 47: 287-291. 